\title{
New sedimentary structures in seismites from SW Tanzania: Evaluating gas- vs. water-escape mechanisms of soft-sediment deformation
}

Hannah L. Hilbert-Wolf ${ }^{\mathrm{a}{ }^{*}}$, Eric M. Roberts ${ }^{\mathrm{a} 2}$, Edward L. Simpson ${ }^{\mathrm{b} 3}$

aDepartment of Earth and Oceans, James Cook University, Townsville, QLD 4811, Australia

${ }^{b}$ Department of Physical Sciences, Kutztown University, Kutztown, PA, 19530, USA

*Corresponding author

${ }^{1}$ hannah.hilbertwolf@my.jcu.edu.au

${ }^{2}$ eric.roberts@jcu.edu.au

${ }^{3}$ simpson@kutztown.edu

\section{ABSTRACT}

Seismite horizons are abundant in Cretaceous sandstones of the Rukwa Rift Basin, southwestern Tanzania. Diverse morphologies of soft-sediment deformation are preserved, including two new, unusual sedimentary structures, herein referred to as: 1) balloon-shaped inflation structures and 2) surface fractures with linked sandstone splays. This original description of new sedimentary structures contributes to the growing catalogue of seismically induced deformation features. Their unusual morphologies bring to the forefront an important, though seldom touched upon, question of how to differentiate between gas- and water-escape in soft-sediment deformation features. The recognition of the spectrum of soft-sediment deformation structures contained in strata and their deformational mechanisms is important because it permits the differentiation between triggering mechanisms, particularly 
seismic activity, and can constrain such events spatially and temporally. We interpret the surface fractures and linked sandstone splays to reflect a high gas effusion rate, formed by the release of high-pressure gas followed by a limited expulsion of water. The balloon-shaped inflation structures reflect lower gas effusion rates due to expulsion of lower pressure gas that did not breach the Cretaceous surface seal. When these gas pulses did breach the paleosurface, they formed gas-discharge pits. These seismogenic structures are consistent with deposition of Cretaceous strata in the Rukwa Rift during periods of active carbonatite volcanism, seismicity, and possibly hot spring activity. This documentation serves as an important data point for the reexamination of the classification scheme of soft-sediment deformation structures as primarily water-escape structures to accommodate for the genesis of some secondary sedimentary features by gas-escape.

Keywords: seismites; gas-escape; water-escape; soft-sediment deformation; paleoseismology; Rukwa Rift Basin.

\section{Introduction}

Soft-sediment deformation is attributed to the overpressuring of pore fluids in unconsolidated sediment, resulting in the modification and often destruction of primary sedimentary structures and the formation of new, secondary sedimentary structures (Lowe, 1975). A variety of mechanisms can initiate such conditions, including: bedform shear, loading, slumping, seismicity, and many other actualistic processes (Allen, 1982; Obermeier, 1996; Owen, 1996; 1997; Jones and Omoto, 2000; Owen and Moretti, 2011). Water is universally called upon as the medium facilitating liquefaction and fluidization. Gases (e.g., biogenic, hydrothermal, etc.) 
however are also a common component of sedimentary environments and may similarly instigate soft-sediment deformation. Although an extensive body of literature on soft-sediment deformation features exists, few studies have actually sought to distinguish between water- and gas-escape mechanisms of deformation and the resultant end products.

The majority of sedimentary structures formed by soft-sediment deformation are attributed to overpressure of the pore fluid, including: convoluted bedding, folding, ball and pillow structures, flame structures, injectites, sand volcanoes, and many more types. Sedimentary structures solely attributable to gas expulsion are rarely documented (Cloud, 1960; Pralle et al., 2003; Jianhua et al., 2004; Frey et al., 2009). Some occurrences of gas-escape through sediments have been reported, although they are dominantly recognized and preserved in argillaceous and marine settings (Fleischer et al., 2001). Examples include: chimneys and pockmarks related to gas hydrates (Cathles et al., 2010), air discharge pits on point bars (Jianhua et al., 2004), molar tooth structures in carbonates (Frey et al., 2009), circular gas-escape pits at a track site (Rindsberg, 2005), and gas bubble release due to biogenic gas build-up (Maxson, 1940; Cloud, 1960).

For soft-sediment deformation structures, the recognition of specific depositional settings, morphologies, and distributions are used to infer genesis via seismicity (McCalpin, 1996; Ettensohn et al., 2002; Reicherter et al., 2009), but identifying the triggering mechanism is often problematic (Owen and Moretti, 2011). Herein, we report on two, new, small-scale soft-sediment deformation features identified in Cretaceous sandstones from the Rukwa Rift Basin, Tanzania. Based on several lines of evidence these features are most likely attributable to seismic activity that caused the overpressuring and subsequent vertical migration of water and gas 
phases responsible for the preserved deformation. The newly identified balloonshaped inflation structures and associated surface fractures with sandstone splays expand the understanding of gas migration effects on the generation of sedimentary structures, particularly in sand-sized sediments, and highlight the importance of considering gas-escape as a formation mechanism for soft-sediment deformation.

\section{Geologic Setting}

The Rukwa Rift Basin (RRB) in southwestern Tanzania is a half-graben basin segment of the western branch of the East African Rift System (EARS; Fig. 1; Chorowicz, 2005). The thick deposits record changes in the kinematic stress regime throughout the polyphase history of the RRB from the Permian to Recent, including multiple phases of rifting (Kilembe and Rosendahl, 1992; Wheeler and Karson, 1994; Delvaux et al., 1998; 2012). The sedimentary packages preserved in the Rukwa Rift are valuable archives of long-lived fluvial and lacustrine deposition and provide key insights into the effects of volcanism and seismicity on deposition in a rift basin through time (Roberts et al., 2010; Hilbert-Wolf and Roberts, 2015).

The RRB records four episodes of rifting and associated sedimentary deposition. The Red Sandstone Group of the RRB was deposited above a thick, Carboniferous-Permian succession (the Karoo Supergroup) after a $\sim 150$ Ma hiatus, and is subdivided into the older Galula Formation and the younger Nsungwe Formation (Roberts et al., 2010). The Galula Formation is assigned a Cretaceous age based on paleontological, geological, and radioisotopic age constraints (Gottfried et al., 2004; Roberts et al., 2004; O’Connor et al., 2006), whereas the Nsungwe Formation has been firmly established as Oligocene, based on radioisotopic dating, magnetostratigraphy, and mammalian biostratigraphy (Roberts et al., 2010, 2012; 
Stevens et al., 2013). The Red Sandstone Group is overlain by the thick, late Neogene to Recent, Lake Beds succession (Grantham et al., 1958) that caps the rift fill sediment and is also an important archive of recent high magnitude seismic activity in the rift (Hilbert-Wolf and Roberts, 2015).

[Insert Fig. 1 here]

The Cretaceous Galula Formation is dominated by cross-bedded sandstones with minor conglomerates and thin mudstones that accumulated in a large amalgamated braided stream setting, which flowed northwest across the continent into the Congo Basin (Roberts et al., 2012). Sedimentation in the overlying Nsungwe Formation is characterized by a vertical progression from alluvial to fluvial to lacustrine settings, which indicates that at least a portion of the western branch of the East African Rift System developed into an internally draining lacustrine basin (Paleo-Lake Rukwa) much earlier than has been recognized previously in the basin or elsewhere along the western branch (Roberts et al., 2012).

Major Late Jurassic to Early Cretaceous rifting is supported by apatite fission track dates from the Rukwa and Malawi Rift flanks (Van der Beek, 1998). Additionally, Delvaux et al. (2012) recognize a succession of rifting stages spanning the Late Cretaceous, Paleogene, and Neogene (components of stress stage 3) that correspond to preserved seismogenic sedimentary structures. Continuous and widespread tectonic activity and associated seismicity during the Cretaceous is clearly recognizable in the Rukwa Rift Basin sandstones (Figs. 2a and 3). Milga (1994) and Roberts et al. (2010) report extensive syndepositional soft-sediment deformation features from the Namba Member of the Galula Formation, including: fluid-escape 
structures, clastic dykes, and growth faulting. These features are linked with intense tectonic activity and the emplacement of local intrusive/extrusive igneous bodies, such as the Panda Hill and Mbalizi carbonatites (Roberts et al., 2010; Fig. 1).

Hydrothermal activity and $\mathrm{CO}_{2}$ vents are current features of the basin system that may also influence the deformation of sediment.

[Insert Fig. 2 here]

\section{Description of soft-sediment deformation}

The soft-sediment deformation features discussed in this paper are located in the Songwe Valley, west of Mbeya, along the TanZam Highway at a locality called TZ7 (Fig. 1). At least four distinct 2-3.5 m-thick horizons with extensive softsediment deformation structures are recognized throughout the exposed Cretaceous Namba Member section. Each is overlain and underlain by undeformed strata and is horizontally continuous for a minimum of $200 \mathrm{~m}$ across the outcrop (Fig. 2b). The deformation includes $\mathrm{cm}$ - to $\mathrm{m}$-scale convoluted bedding, folds, and flame structures preserving evidence of fluidization and water-escape (Fig. 3).

[Insert Fig. 3 here]

The two new types of soft-sediment deformation features we report from the Cretaceous Namba Member include: 1) balloon-shaped inflation structures and 2) associated linear surface fractures with linked sandstone splays. The site preserving these features is located in the middle part of the Namba Member of the Galula Formation, roughly $8 \mathrm{~m}$ above the base of the local section, in a three-dimensionally 
exposed outcrop (Fig. 2b). This interval is characterized by a series of upward-fining, medium- to fine-grained arkosic to sub-arkosic sandstones with erosive, basal pebble lags and well-developed, medium-scale trough and tabular cross-stratification throughout (Roberts et al., 2004; 2010). The inflation structures and surface fractures occur in the lowest recognized seismite horizon, specifically in an amalgamated tabular sandstone bed. They occur near the up-dip portion of one of many, small synsedimentary growth faults that are located in this part of the stratigraphy (Fig. 2a), dominated by a large braid plain system. Relative to the preserved Cretaceous land surface, the balloon structures and expulsion cracks with sandstone splays represent both near subsurface- and surface-linked, soft-sediment deformation features.

\subsection{Inflation structures and gas-discharge pits}

The inflation structures consist of an upper oblate spheroid- to teardropshaped chamber connected to a narrow cylindrical shaft that widens vertically from sub-cm to $1 \mathrm{~cm}$ or more in diameter (Figs. 4 and 5). Most shafts originate in an underlying structureless to weakly stratified sandstone bed, bend at varying angles and crosscut planar to low-angle stratification (Fig. 4). Internally, the shafts consist of massive, fine- to medium-grained sandstone with no discernable difference in grain size from the surrounding sediments. At their uppermost extent, just below the paleosurface, the shafts are connected to asymmetrical ovoid structures. The ovoid structures are wider near the tops than at the bases, resembling the shape of an inflated balloon (Figs. 4 and 5), and range from 3-10 cm in diameter. Finer-grained sandstone appears in the outer shell of the ellipsoid compared to the core sandstone. Some ovoid structures deflect the overlying stratified sandstone beds vertically into small anticlines that commonly encase multiple asymmetrical ovoid structures (Fig. 
4). Inflation structures occur in isolation (Fig. 5) as well as in small clusters (Fig. 4). Many of the inflation structures breach the paleosurface and are preserved in planar cross-section as circular pits with concentric, fine-grained sandstone laminations (Fig. $5 b)$.

[Insert Fig. 4 and Fig. 5 here]

\subsection{Surface fractures with sandstone splays}

Surface fractures are structures formed by fluidized conduits that have breached the paleosurface (Fig. 6). The surface fractures are restricted to the top of the unit and bend the upper $15-50 \mathrm{~cm}$ of fine- to medium-grained, low-angle laminated sandstone immediately surrounding the conduit upward (bent perpendicular to the undisturbed bedding; Fig.7). In the subsurface the conduits crosscut low-angle, stratified sandstone and originate from an underlying structureless to weakly stratified sandstone bed. Internally the conduits have vertically oriented, irregular-shaped, and upward bending folded laminations. The slightly sinuous cracks on the paleosurface display numerous associated smaller splay fractures (Fig. 6). The surface and subsurface strata are upturned adjacent to, and paralleling, the fractures.

[Insert Fig. 6 and Fig. 7 here]

A key feature of surface fractures is the common co-occurrence of narrow, linear to branching networks of finger-like sandstone that emanate from the numerous expulsion cracks (Fig. 6). These features are termed "sandstone splays" and together, both surface fractures and sandstone splays are observed in the same bed and horizon 
as the balloon-like inflation structures. Sandstone splays branch in a dendritic pattern and represent granular flows that moved down-slope of the paleo-topographic surfaces onto lower elevations on the undisturbed sandstone surface (Fig. 6). Splay sandstones display no apparent internal structure nor do they change in grain size along the length of the splay, but do show a decrease in flow thickness away from the rupture breach.

\section{Interpretations and Discussion}

\subsection{Evidence for a seismic origin}

A succession of rift stages affected the Tanganyika-Rukwa-Malawi lineament during the Cretaceous (Delvaux et al., 2012), repeatedly reactivating the structural weaknesses in the Precambrian basement underlying the RRB. Thermochronology studies have identified evidence for Late Jurassic-Early Cretaceous rifting (Van der Beek et al., 1998). Continent-scale tectonic reactivation of major rifts and structural sutures is recognized from 140-120 Ma (Foster and Gleadow, 1992) and is related to far-field stresses associated with the rifting of the African and South American plates. These tectonic events are often associated with syntectonic Cretaceous sedimentary successions (Roberts et al., 2010). Additionally, within a few kilometers of the study area are the Panda Hill and Mbalizi carbonatite volcanoes, which were putatively active during the Cretaceous (Pentelkov and Voronovskii, 1977; Van Straaten, 1989). Crosscutting field relationships and volcaniclastic sediments in the Namba Member strongly suggest that the Namba Member was deposited contemporaneously with the carbonatite volcanism (Fawley and James, 1955; Roberts et al., 2010). Throughout the Cretaceous Galula Formation sandstones, there are abundant and repeated horizons that show evidence for laterally continuous liquefaction and fluidization. In some 
cases, soft-sediment deformation features in the Namba Member have been directly traced back to syndepositional faults in the rift basin (Fig. 2a; Roberts et al., 2010). More specifically, the inflation structures and surface fractures described here occur directly in a line with a series of small, syndepositional normal faults that are observed a short distance away at the top of a highly deformed, $2.5 \mathrm{~m}$-thick interval with convoluted bedding, folded laminations and fluidized beds (Fig. 2a). The presence of these soft-sediment deformation features in a long-lived half-graben basin, directly linked with syndepositional growth faults, points to a seismic trigger for the soft-sediment deformation, and hence these newly reported sedimentary structures are best interpreted as seismites.

Although the presence of soft-sediment deformation features such as convoluted bedding, flame structures and other features in these deposits can easily be explained by liquefaction and fluidization of water and sediment during seismic shaking, the morphologies of the newly documented balloon-shaped inflation structures and surface fractures with sandstone splays are unique in the sedimentary record. Comparison with recent empirical investigations suggests an additional element of gas-escape was significantly involved in their genesis.

\subsection{The role of gas-escape in soft-sediment deformation}

\subsubsection{Formation of inflation structures and gas-discharge pits}

The balloon-shaped inflation structure, consisting of a subvertical, cylindrical shaft leading to a larger, ovoid form, is a unique sedimentary structure formed via gas-expulsion near, but not breaching, the paleosurface. Experiments illustrate a significant morphological difference between water- and gas-escape generated structures (Furniss et al., 1998; Frey et al., 2009). Comparable to experimental 
structures formed by Furniss et al. (1998) and Frey et al. (2009), gas moved upwards through the sandstone in straight to semi-winding paths, probably following minor heterogeneities in the sediments, until it reached a barrier and stalled, as an ovoid chamber, a typical gas bubble morphology (Fig. 8; Boudreau, 2012). As the ovoid-tospherical bubble grows in soft, sandy sediment, the pressure difference between the tip and the tail of the bubble becomes larger, and the bubble shape deviates from an oblate spheroid, adopting an inverted teardrop shape, as seen in the preserved balloonshaped inflation structures (Figs. 4 and 5; Boudreau et al., 2005; Boudreau, 2012).

[Insert Fig. 8 here]

The shafts are preserved fractures in soft-sediments through which gases rose (i.e., creation of a bubble tube or path, sensu Boudreau et al., 2005). The multidirectional shafts are likely an indication that the gas was under low pressure, as slight differences in the permeability of surrounding sediments deflected the gas escape path. Sediments experiencing liquefaction and fluidization (e.g., due to earthquake activity) could provide such a low-pressure, low yield-strength environment. Experiments of bubble propagation through soft-sediment and observations in the rock record generally report on muddy sediment and/or movement through gelatin. The structures reported here are consequential in that they preserve movement paths (shafts) through fine- to medium-grained sand, a less elastic medium in comparison to mud. Most balloon structures are oriented vertically, however, a few are subvertical with shafts preserved near-parallel to the bedding (Fig. 5a). In these cases, gas bubbles moved laterally along more permeable bedding planes when the vertical resistance was encountered (e.g., Boudreau et al., 2005). 
Under abnormal stress, as gas moves through water-saturated sediment, the sediment dewaters and increases the viscosity of the surrounding material over time (Furniss et al., 1998). The closer to the surface the gas moved, the more viscous, and impermeable the surrounding sand became, eventually trapping the gas, where it formed ovoids. In addition to this autogenic control, timing might have also played a role in impeding gas movement. During liquefaction, due to the loss of grain-to-grain contacts, sediment behaves as a viscous fluid with little or no yield strength (Owen and Moretti, 2011). After liquefaction, grains settle to close packing, leading to the displacement of excess pore fluid (Owen and Moretti, 2011). Assuming the sediment underwent liquefaction and fluidization, then it is possible that the gas flowed freely while the yield strength of the sediment was reduced, and was trapped following fluid expulsion and subsequent 'stiffening' of the surrounding sand via dewatering. The rising gas pulled sediment entrained in water behind it, effectively pumping the pores and also leading to compaction of the sediment. When conditions were right to prevent the gas from moving towards the surface, the gas expanded at the end of its trail (the preserved shafts), creating the ovoid structures (Fig. 8). This bubble morphology mimics the results of numerical experiments by Katsman (2015) who showed that methane bubbles achieve an inverted teardrop shape and are much bigger and more inflated when moving through stronger, coarser sediment with a high value of fracture toughness.

The ovoid structures and up-warped, anticlinal laminations above collection points of multiple balloon structures are evidence for impeded gas movement (Fig. 4). These accumulations of gas bubbles created gas domes (Fig. 8), some of which erupted, forming surface fractures (see section 4.2.2). Early cementation or a biogenic mat may have formed a less-permeable Cretaceous surface, trapping the gas as 
individual ovoids, or together in pockets. At higher effusive rates or where slight differences in surface permeability existed, the gas bubbles breached the paleosurface, forming gas-discharge pits (Fig. 5; sensu Jianhua et al., 2004). The concentric fabric in both subsurface and ruptured (gas-discharge pits) inflation structures is attributable to gas pulses through a single conduit that pulled along pulses of watery sediment (Cloud, 1960). An upward directed flow generated in the wake of the bubbles entrains and transports sediment. The fine-grained outer laminae of the ovoids may represent the initial sediments that were more easily transported by the gas. The ovoid chambers of the inflation structures were eventually filled by watery sediment as the gas escaped via hair-like cracks and/or dissolving into the water. Vertical conduits and concentric laminations in air-discharge pits have previously been attributed to gas-escape features on the Yellow River delta plain (Jianhua et al., 2004). According to Jianhua et al., (2004), air-discharge pits form only in the presence of water, where the environment is pressurized enough for gas to 'erupt' and form a pit.

\subsubsection{Formation of surface fractures with sandstone splays}

The surface fractures with associated sandstone splays are evidence of overpressured gas rupturing the early-cemented Cretaceous paleosurface forming a linear fracture (Fig. 8). This is comparable to experiments by Frey et al. (2009) where gas bubbles were observed moving upwards in long, linear fractures. In contrast to the inflation structures described above, the surface fractures represent higher gas effusion rates. The build-up of gas bubbles (now preserved as balloon-shaped inflation structures) beneath an impassable layer suggests permeability heterogeneities in the Namba Member that impeded vertical gas movement. Once formed, the path of a gas bubble is slow to anneal (Boudreau et al., 2005) and so 
becomes a conduit for the movement of subsequent gas bubbles. At such obstructions, gas likely accumulated and built up to a critical pressure, fracturing the overlying sediment and erupting onto the surface (e.g., Boudreau et al., 2005). The flanks of the surface fractures are marked by upward turned (nearly vertical) laminations (Fig. 7). This characteristic upward warping of laminations is considered a critical point of differentiation of gas-escape, as compared to water-escape, in experiments of Frey et al. (2009). Continued passage of gas bubbles created chaotic and convoluted bedding in the conduits leading to the surface fractures (also noted by Frey et al., 2009). Subsurface cracks commonly coalesce into conduits or ruptures that may breach the sediment surface, forming mud volcanoes, individual sediment flows, or pools of sediment (Nichols et al., 1994; Pralle et al., 2003; Ross et al., 2011). The thin, fingerlike, branching sand splays preserved on the bottom, distal edges of the crack flanks likely formed as small-scale hyperconcentrated flows that were entrained in the wake of moving gas, erupted at the paleosurface, flowed down the flanks of the surface fractures towards topographic lows, and then frictionally froze due to rapid dewatering. Similar gas-driven water expulsion is reported from gas chimneys, which are known to propel water upwards (Cathles et al., 2010).

Experimentally, gas-generated features are not symmetrically distributed across the surface, but cluster due to heterogeneities (e.g., bioturbation, crosslaminations, etc.) in the subsurface (Pralle et al., 2003). Heterogeneities are best called upon to explain the horizontal variation in the Cretaceous gas features described here. Additionally, in experiments Pralle et al. (2003) observed that the main formation phase of gas-escape structures was swift (30 minutes) and the interstitial fluid flow due to excess pore pressure causing fluids to migrate vertically destroyed the structure over the following 12 hours. 


\subsection{A model for gas-generated seismites in the Rukwa Rift}

Gas saturated pore waters necessary to produce the features documented in the study area were likely generated and overpressured due to seismic activity along localized faults, as suggested by the region's active tectonic history. We hypothesize that seismicity generated overpressured gas pulses that were released and migrated through the ground water system, deforming the sediment as the gas passed through (Fig. 8; e.g., Pralle et al., 2003; Frey et al., 2009; Ross et al., 2011). The gas likely moved through the sediment in the form of bubbles (aggregative fluidization), as the density contrast between the fluid and sediment is high (Allen, 1982; Frey et al., 2009). Under static loading conditions, gas bubbles tend to be stable (Wheeler, 1990).

Weakening the surrounding sediment can induce gas bubble movement. Cyclic stresses from seismic activity can initiate liquefaction (Owen and Moretti, 2011), creating the conditions necessary to release gas bubbles (Wheeler, 1990). There are few reported examples of shallow, gas-generated features associated with modern earthquakes with which to compare these structures from the Namba Member. Examples include coseismic gas generation by the 7.7 magnitude Bhuj earthquake, as documented by surface vents without associated sand volcanoes and then late stage fluid leakage vents with associated sand volcanoes (Rajendran et al., 2001), and the deformation of clay sediments by $\mathrm{CO}_{2}$ gas jets associated with seismicity along a shear zone (Bankwitz et al., 2003).

However, taking into consideration the depositional and tectonic environments, morphologies and spatial relationship between these sedimentary structures, and by comparison with the literature and experimental works, the inflation structures and surface fractures reported here most likely formed primarily by gasescape, with a minor component of water-escape, close to and at the paleosurface of 
an ancient channel bank deposit (Fig. 8). An initial gas expulsion phase is favored for the generation of these structures rather than water because of: 1) an absence of extensive water-related fluidization features, such as sand volcanoes, sediment pools, and down-turned laminations (e.g., Montenat et al., 2007), and 2) the manner in which the physical structure of balloon-shaped inflation structures appears to mimic gas expansion. The inflation structures are likely shallow subsurface structures formed by lower gas effusion rates, and where they breached the paleosurface, formed gasdischarge pits, comparable to those described by Jianhua et al. (2004; "air-discharge pits" from modern fluvial deposits from the Yellow River). The surface fractures with linked sandstone splays also formed primarily through gas-discharge. The large sandstone conduits linked to the surface fractures reflect a greater effusive rate than the cylindrical shafts linked to the balloon structures, which more aggressively ruptured the paleosurface. This argument is based on conduit diameters, evidence of generation and deformation of internal laminations, as well as potential for paleosurface breaching and deformation. Missing from the Cretaceous pedogenic surface is evidence of large amounts of elutriated sediment, indicating that water was less likely involved in the deformation process than was gas.

Changes in porosity and pressure due to seismic stresses are capable of initiating gas release, and/or increasing gas release rates. Genetic relationships between seismicity and gas discharge of carbon dioxide (Irwin and Barnes, 1980; Mörner and Etiope, 2002), methane (Etiope and Klusman, 2002), and radon (Hauksson, 1981) have been documented. The nearby Panda Hill carbonatite complex represents a proximal source of seismicity in the Rukwa Rift that might best explain the abundance of small-scale syndepositional faulting and seismite features documented in the study area. Pulses of overpressured gas during Cretaceous 
deposition in the Rukwa Rift Basin may have also been generated by this volcanic/seismic activity. Potential gas sources include: collapsed pores, fractured interbedded anoxic lacustrine deposits $\left(\mathrm{CH}_{4}\right)$, volcanogenic degassing $\left(\mathrm{CO}_{2}\right), \mathrm{CO}_{2}$ released from hydrothermal springs, and/or thermogenic gas from the underlying Karoo shales. Non-marine limestone is reported from the Galula Formation near Usevia and may also indicate a hydrothermal gas source, similar to the present-day $\mathrm{CO}_{2}$-rich geothermal system in the Mbeya area.

\section{Summary}

Cretaceous rift strata in Tanzania exhibit unique sedimentary structures developed in a low ground water setting, including: 1) balloon-shaped inflation structures and 2) surface fractures with linked sandstone splays. The expressions of soft-sediment deformation are attributable to localized seismic events in the Cretaceous East African Rift that generated gas release coupled with a subsequent water-escape phase. These new sedimentary structures are easily recognizable and allow more detailed interpretation of the impact of seismic activity, and generally of gas-release by any triggering mechanism. Observations further support the possibility of preserving gas-escape related deformation structures in the rock record, and emphasize the significant role gas can play as an agent of sediment transport and mechanism of sedimentary structure formation and alteration. For shallow deformation within 10 meters of the surface, over pressuring of water rather than gas is more often called upon to generate soft-sediment deformation associated with seismic activity (Obermeier, 1996). However, gas-generated soft-sediment deformation features are observed (Jianhua et al., 2004) and experimentally generated (Wheeler, 1990; Furniss et al., 1998) in near-surface environments. Although gas- 
escape generated sedimentary structures are rarely identified from ancient environments, they are likely more common than documentation reveals due to the difficulties in differentiating between gas- and water-escape mechanisms. It is important to continue to refine the classification schemes for soft-sediment deformation structures to accommodate for the genesis of sedimentary structures by gas-escape, which is traditionally not appreciated, and it is fruitful to investigate both empirically and experimentally.

\section{Acknowledgments}

We thank the National Science Foundation (EAR-0617561) and the National Geographic Society (Committee for Research and Exploration) for funding. Logistical support and permits were provided by Tanzanian Commission for Science, Technology and the Tanzanian Antiquities Unit and field assistance from team members P. O’Connor, N. Stevens, C. Mtelela, Z. Jinnah, J. Temba, and S. Ngasala. B. Downey and M. Hendrix also provided important feedback. We thank Elizabeth Heness for reading an early draft.

\section{References}

Allen, J.R.L., 1982. Sedimentary Structures: Their character and physical basis. Developments in Sedimentology, 30B. Elsevier, Amsterdam, 663 p. Bankwitz, P., Bankwitz, E., Bräuer, K., Kämpf, H., Störr, M., 2003. Deformation structures in Plio- and Pleistocene sediments (NW Bohemia, Central Europe). In: Van Rensbergen, P., Hillis, R.R., Maltman, A.J., Morley, C.K., (Eds.), Subsurface Sediment Mobilization. Geological Society, London, Special Publications 216, pp. 73-93. 
Boudreau, B.P., Algar, C., Johnson, B.D., Croudace, I., Reed, A., Furukawa, Y., Dorgan, K.M., Jumars, P.A., Grader, A.S., 2005. Bubble growth and rise in soft sediments. Geology 33, 517-520.

Boudreau, B.P., 2012. The physics of bubbles in surficial, soft, cohesive sediments. Marine and Petroleum Geology 38, 1-18.

Cathles, L.M., Su, Z., Chen, D., 2010. The physics of gas chimney and pockmark formation, with implications for assessment of seafloor hazards and gas sequestration. Marine and Petroleum Geology 27, 82-91.

Chorowicz, J., 2005. The East African Rift System. Journal of African Earth Sciences $43,379-410$.

Cloud, P.E., Jr., 1960. Gas as a sediment and diagenetic agent. American Journal of Science, Bradley Volume 258-A, 35-45.

Delvaux, D., Kervyn, F., Vittorl, R.S., Kajara, E., Kilembe, S.A., 1998. Late quaternary tectonic activity and lake level change in the Rukwa Rift Basin. Journal of African Earth Sciences 26, 397-421.

Delvaux, D., Kervyn, F., Macheyeki, A.S., Temu, E.B., 2012. Geodynamic significance of the TRM segment in the East African Rift (W-Tanzania): active tectonics and paleostress in the Ufipa plateau and Rukwa basin. Journal of Structural Geology 37, 161-180.

Etiope, G., Klusman, R. W., 2002. Geologic emissions of methane to the atmosphere. Chemosphere 49 (8), 777-789.

Ettensohn, F.R., Rast, N., Brett, C.E., (Eds.), 2002. Ancient Seismites. Geological Society of America Special Publication 359, 200 pp.

Fawley, A.P., James, T.C., 1955. A pyrochlore carbonatite from Southern Tanganyika. Economic Geology 50, 571-585. 
Fleischer, P., Orsi, T. H., Richardson, M. D., Anderson, A. L., 2001. Distribution of free gas in marine sediments: a global overview. Geo-Marine Letters 21, 103122.

Foster, D.A., Gleadow, A.J.W., 1992. The morphotectonic evolution of rift margin mountains in central Kenya — constraints from apatite fission track thermochronology. Earth and Planetary Science Letters 113, 157-171.

Frey, S.E., Gingras, M.K., Dashtgard, S.H., 2009. Experimental studies of gas-escape and water escape structures: mechanisms and morphologies. Journal of Sedimentary Research 79, 808-816.

Furniss, G., Rittel, J. F., Winston, D., 1998. Gas bubble and expansion crack origin of "molar-tooth" calcite structures in the middle Proterozoic belt Supergroup, western Montana. Journal of Sedimentary Research 68, 104-114.

Gottfried, M.D., O’Connor, P.M., Jackson, F.D., Roberts, E.M., Chami, R., 2004. Dinosaur eggshell from the Red Sandstone Group of Tanzania. Journal of Vertebrate Paleontology 24, 494-497.

Grantham, D.R., Teale, E.O., Spurr, A.M., Harkin, D.A., Brown, P.E., 1958. Quarter Degree Sheet 244 (Mbeya). Geological Survey of Tanganyika, Dodoma.

Hauksson, E., 1981. Radon content of groundwater as an earthquake precursor: Evaluation of worldwide data and physical basis. Journal of Geophysical Research. DOI: 10.1029/JB086iB10p09397.

Hilbert-Wolf, H.L., Roberts, E.M., 2015. Giant seismites and megablock uplift in the East African Rift: Evidence for Late Pleistocene large magnitude earthquakes. PLOS One 10 (6): e0129051. DOI: 10.1371/journal.pone.0129051.

Irwin, W.P., Barnes, I., 1980. Tectonic relations of carbon dioxide discharges and earthquakes. Journal of Geophysical Research 85, 3115-3121. 
Jianhua, Z., Zhifeng, W., Guanmin, W., Xibin, W., Hongbo, L., Xiaohua, S., 2004. Air-charge pits on the Yellow River delta plain. Sedimentary Geology 170, 120.

Jones, A.P., Omoto, K., 2000. Towards establishing criteria for the identifying trigger mechanisms for soft-sediment deformation: A case study of Late Pleistocene lacustrine sands and clays, Onikobe and Nakayamadaira Basins, northeastern Japan. Sedimentology 47, 1211-1226.

Katsman, R., 2015. Correlation of shape and size of methane bubbles in fine-grained muddy aquatic sediments with sediment fracture toughness. Journal of Structural Geology 70, 56-64.

Kilembe, E.A., Rosendahl, B.R., 1992. Structure and stratigraphy of the Rukwa rift. Tectonophysics 209, 143-158.

Lowe, D.R., 1975. Water escape structures in coarse-grained sediments. Sedimentology 22, 157-204.

Maxson, J. H., 1940. Gas pits in non-marine sediments. Journal of Sedimentary Petrology 10, 142-145.

McCalpin, J., (Ed.), 1996. Paleoseismology. Academic Press, New York, 588 pp.

Milga, N.R., 1994. Depositional environments, stratigraphy and hydrocarbon potential of the Rukwa Rift Basin-SW Tanzania. Ph.D. Dissertation, Duke University, 156p.

Mörner, N.-A., Etiope, G., 2002. Carbon degassing from the lithosphere. Global Planetary Change 33, 185-203.

Montenat, C., Barrier, P., Ott d'Estevou, P., Hibsch, C., 2007. Siesmites: An attempt at critical analysis and classification. Sedimentary Geology 196, 5-30.

Nichols, R.J., Sparks, R.S.J., Wilson, C. J. N., 1994. Experimental studies of the 
fluidization of layered sediments and the formation of fluid escape structures. Sedimentology 41, 235-253.

Obermeier, S.F., 1996. Use of liquefaction-induced features for paleoseismic analysis - An overview of how seismic liquefaction features can be distinguished from other features and how their regional distribution and properties of source sediment can be used to infer the location and strength of Holocene paleoearthquakes. Engineering Geology 44, 1-76.

O’Connor, P.M., Gottfried, M.D., Stevens, N.J., Roberts, E.M., Ngasala, S., Kapilima, S., Chami, R., 2006. Dinosaurs and other vertebrates from the Cretaceous Red Sandstone Group, Rukwa Rift Basin, Southwestern Tanzania. Journal of African Earth Sciences 44, 277-288.

Owen, G., 1996. Experimental soft-sediment deformation: structures formed by liquefaction of unconsolidated sands and some ancient examples. Sedimentology 43, 270-293.

Owen, G., 1997. Deformational processes in unconsolidated sands. In: Jones, M.E., Preston, R.M.F., (Eds.), Deformation of sediments and sedimentary rocks. Geological Society of London Special Publication 29, pp. 137-146.

Owen, G., Moretti, M., 2011. Identifying triggers for liquefaction-induced softsediment deformation in sands. Sedimentary Geology 235, 141-147.

Pentelkov, V.G., Voronovskii, S.N., 1977. Absolute age of Mbalizi carbonatites, Tanzania, and its correlation with age of other carbonatites from RukavaMalavi Rift Zone. Doklady Akademii Nauk SSSR 235, 1136-1139.

Pralle, Norbert, Külzer, M., Gudehus, G., 2003. Experimental evidence on the role of gas in sediment liquefaction and mud volcanism. In: Jones, M.E., Preston, R.M.F., (Eds.), Deformation of sediments and sedimentary rocks. Geological 
Society of London Special Publication 216, pp. 159-171.

Rajendran, K., Rajendran, C.P., Thakkar, M., Tuttle, M.P., 2001. The 2001 Kutch (Bhuj) earthquake: Coseismic surface features and their significance. Current Science 80, 1397-1405.

Reicherter, K., Michetti, S.M., Silva, P.G., 2009. Palaeoseismology: historical and prehistorical records of earthquake ground effects for seismic hazard assessment. In: Reicherter, K., Michetti, S.M., Silva, P.G., (Eds.), Palaeoseismology: historical and prehistoric records of earthquake ground effects for seismic hazard assessment: Geological Society, London, Special Publication 316, pp. 1-10.

Rindsberg, A., 2005. Gas-escape structures and their paleoenvironmental significance at the Steven C. Minkin Paleozoic footprint site (Early Pennsylvanian, Alabama). In: Buta, R. J., Rindsberg, A. K., \& Kopaska-Merkel, D. C., (Eds.), Pennsylvanian footprints in the Black Warrior Basin of Alabama. Alabama Paleontological Society Monograph no. 1, pp. 177-183.

Roberts, E.M., O’Connor, P.M., Gottfried, M.D., Stevens, N.J., Kapilima, S., Ngasala, S., 2004. Revised stratigraphy and age of the Red Sandstone Group in the Rukwa Rift Basin, Tanzania. Cretaceous Research 25, 749-759.

Roberts, E.M., O’Connor, P.M., Stevens, N.J., Gottfried, M.D., Jinnah, Z.A., Ngasala, S., Choh, A.M., Armstrong, R.A., 2010. Sedimentology and depositional environments if the Red Sandstone Group, Rukwa Rift Basin, southwestern Tanzania: New insight into Cretaceous and Paleogene terrestrial ecosystems and tectonics in sub-equatorial Africa. Journal of African Earth Sciences 57, 179-212.

Roberts, E.M., Stevens, N.J., O’Connor, P.M., Dirks, P.G.H.M., Gottfried, M.D., 
Armstrong, R.A., Clyde, W.C., Kemp, A.I.S., Hemming, S., 2012. Initiation of the western branch of the East African Rift coeval with the eastern branch. Nature Geoscience 5, 289-294.

Ross, J.A., Peakall, J., Keevil, G.M., 2011. An integrated model of extrusive sand injectites incohesionless sediments. Sedimentology 58, 1963-1715.

Stevens, N.J., Seiffert, E.R., O’Connor, P.M., Roberts, E.M., Schmitz, M.D., Krause, C., Gorscak, E., Ngasala, S., Hieronymus, T.L., Temu, J., 2013. Palaeontological evidence for an Oligocene divergence between Old World monkeys and apes. Nature 497, 611-614.

Van der Beek, P., Mbede, E., Andriessen, P., Delvaux, D., 1998. Denudation history of the Malawi and Rukwa Rift flanks (East African Rift System) from fission track thermochronology. In: Delvaux, D., Khan, M.A. (Eds.), Tectonics, sedimentation and volcanism in the East African Rift System. Journal of African Earth Sciences 26, pp. 363-385.

Van Straaten, P., 1989. Nature and structural relationships of carbonatites from Southwestern and West Tanzania. In: Bell, K. (Ed.), Carbonatites. UnwinHyman, London, pp. 177-199.

Wheeler, S.J., 1990. Movement of large gas bubbles in unsaturated fine-grained sediments. Marine Geotechnology 9, 113-129.

Wheeler, W.H., Karson, J.A., 1994. Extension and subsidence adjacent to a "weak" continental transform: An example from the Rukwa rift, East Africa. Geology $22,625-628$

\section{Figure Captions}

Fig. 1. Locality maps of the study site in the Rukwa Rift Basin. (a) Inset map showing 
the general location of the study area (yellow box) within eastern Africa. (b) Map of eastern Africa, highlighting the Tanganyika-Rukwa-Malawi rift segments. The arrow marks the study site in the Rukwa Rift Basin, southwestern Tanzania. Maps are modified from the NASA Shuttle Radar Topography Mission collection (http://www2.jpl.nasa.gov/srtm/cbanddataproducts.html). (c) Detailed geologic map of the TZ7 site in the Songwe sub-basin of the Rukwa Rift displaying volcanic and structural features (modified from Roberts et al., 2010).

Fig. 2. Stratigraphic section and field photo of syndepositional growth faults. (a) Growth faults in the Namba Member found along a linear trend in close proximity $(<$ $50 \mathrm{~m}$ away) to soft-sediment deformation structures. (b) Stratigraphic section through the TZ7 study site highlighting horizons affected by seismogenic soft-sediment deformation. See Roberts et al. (2004) for a detailed stratigraphic section through the Namba Member at the TZ7 site.

Fig. 3. Field photographs of seismogenic soft-sediment deformation features recorded throughout the Cretaceous red-beds of the Rukwa Rift Basin. (a) Folded, convoluted units showing evidence of fluidization. (b) Load structures and diapir-like features. The plastic intrusion furthest to the left shows evidence of halted injection. (c) Detached load structures. (d) Fluidized and folded beds with diapir-like structure.

Fig. 4. Field photographs of balloon-shaped inflation structures in the Cretaceous Namba Member. (a) Note the upward-arching laminations and clustering of ovoid structures at the crest. Low-angle stratification is preserved above the structures, and massive sandstone is present below the structures. (b) Line sketch highlighting 
individual inflation structures within the gas-cluster of (a). (c) Time-series cartoons illustrating the likely genesis of inflation structures and surficial gas-discharge pits. At $\mathrm{t}=3$, heterogeneities in the Namba Member sediments trapped some rising gas bubbles (forming balloon-shaped inflation structures), while other gas bubbles successfully rise to the paleosurface and rupture $(\mathrm{t}=4)$, forming gas-discharge pits.

Fig. 5. Field photographs of inflation structure and gas-discharge pit. (a) Isolated, asymmetric ovoid structure and winding shaft. The ovoid inflation structure is oriented near-parallel to the bedding and the shaft crosscuts $\mathrm{cm}$-scale bedding below the ovoid structure. Note the fine laminations preserved in the top half of the ovoid feature that parallel the ovoid edge. (b) A gas-discharge pit, preserving the rupture of gas onto the paleosurface. No obvious shaft is visible, although there is a suspicious conduit-like feature on the left side of the ovoid. Note the concentric laminations.

Fig. 6. Field photographs of surface fractures with linked sandstone splays in the Namba Member. (a) Irregular surface rupture with upward bending of laminations. Sandstone splays run from the highest to the lowest elevations of the flanks of the fractures and run out onto the Cretaceous land surface. Left scale bar is in $\mathrm{cm}$. (b) Surface fractures with linked sandstone splays. Note the reduction in thickness of the splay away from the rupture. Top scale bar is in $\mathrm{cm}$. (c) Rose diagrams illustrating the near-perpendicular orientations of the sandstone splays with the strike of the paleosurface, documenting that these hyperconcentrated flows moved down the Cretaceous topography.

Fig. 7. Field photographs illustrating fluidized sandstone conduits and various 
interactions with the paleosurface in the Namba Member. Upper scale bars in photographs are in $\mathrm{cm}$. (a) Cross section view of sandstone conduit. Note the truncation of near horizontal stratification, terminated vertically trending stratification, and the conduit surface rupture. Top scale bar is in $\mathrm{cm}$. (b) Crosssection of fluidized sandstone conduit and associated surface fracture. No expelled material is evident on the paleo-surface. (c) Cross section of sandstone conduit. Note truncation of near horizontal stratification and complexly folded internal stratification. The conduit deforms the top laminations into a dome shape, but does not breach the paleosurface. Top scale bar is in $\mathrm{cm}$. (d) Fluidized sand erupting from the surface fracture.

Fig. 8. Time-series cartoon illustrating the genesis of the newly described sedimentary features primarily by gas expulsion. White-grey colors indicate gas, and blue colors indicate a secondary water component. Heterogeneities in the sediment deflected, impeded, and facilitated gas-escape, as manifested by the variety of sedimentary structures preserved in different stages of gas- and water-escape onto the paleosurface. $\mathrm{a}$ - inflation structure, see Fig. 5a; $\mathrm{b}$ - collection of gas bubbles forming a gas dome, see Fig. 4; c - gas-discharge pit, see Fig 5b; d-surface fracture, see Figs. $6 \& 7$; e - sandstone splays, see Fig. 6. 


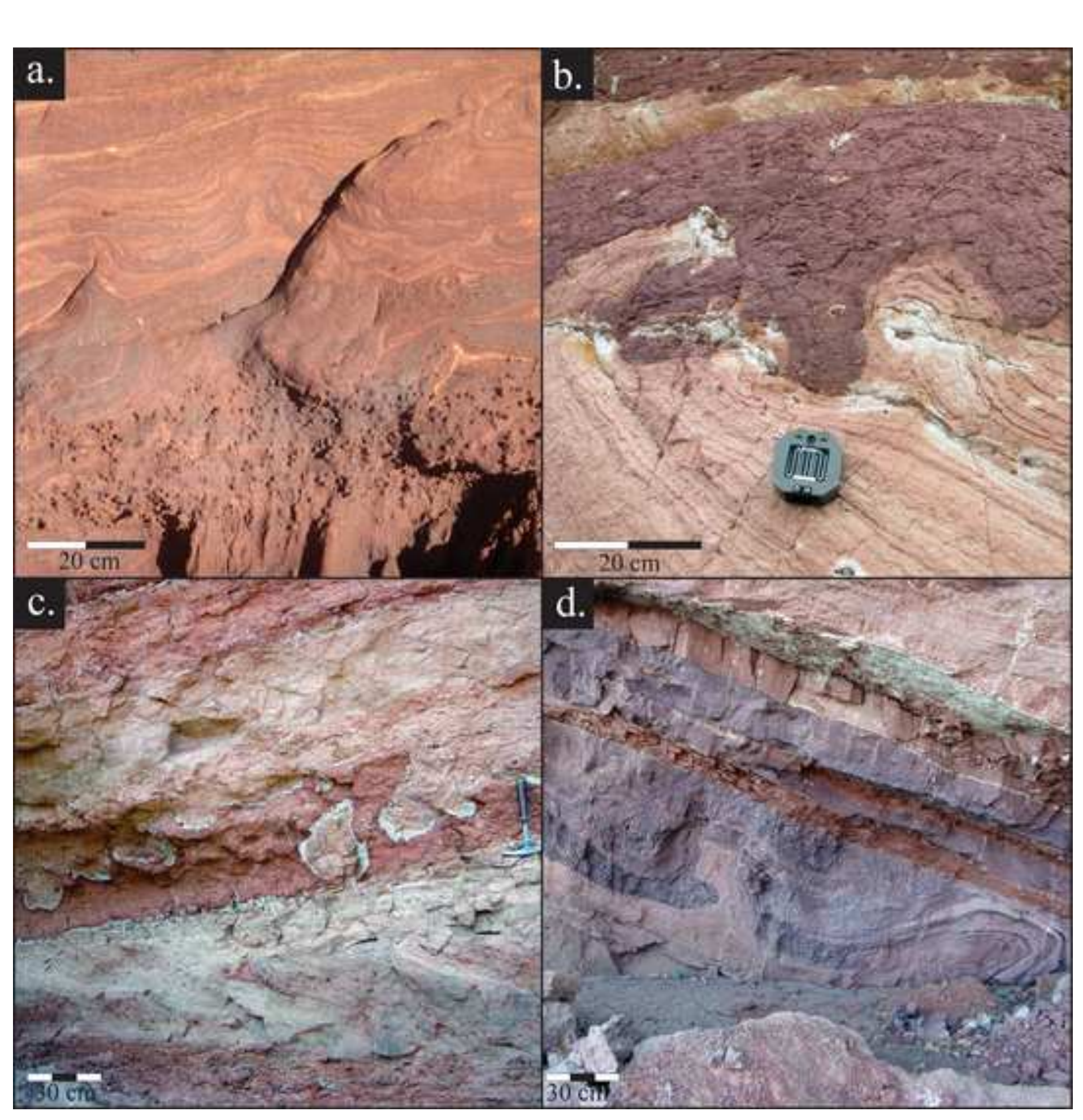

\section{(a)}




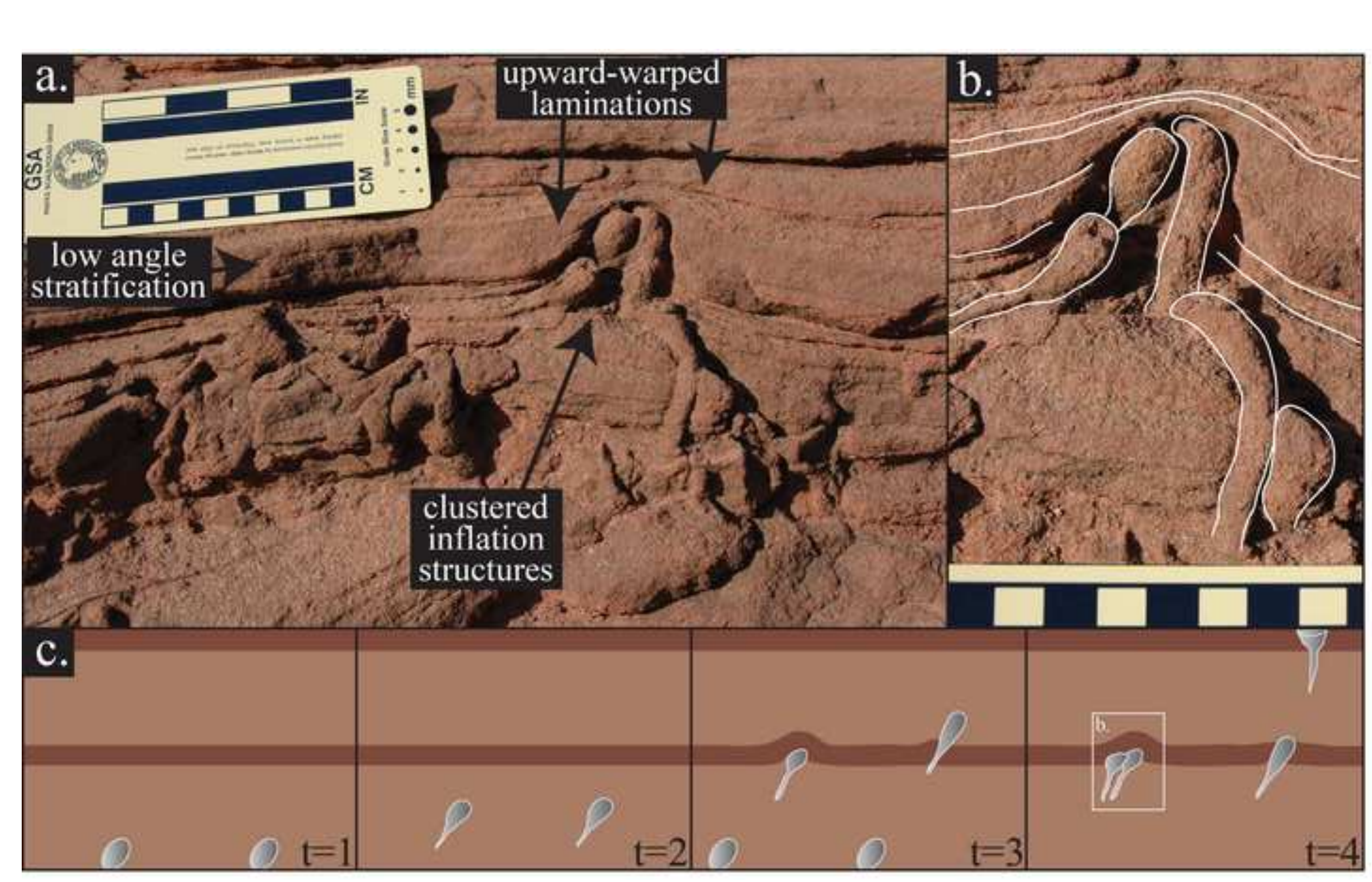




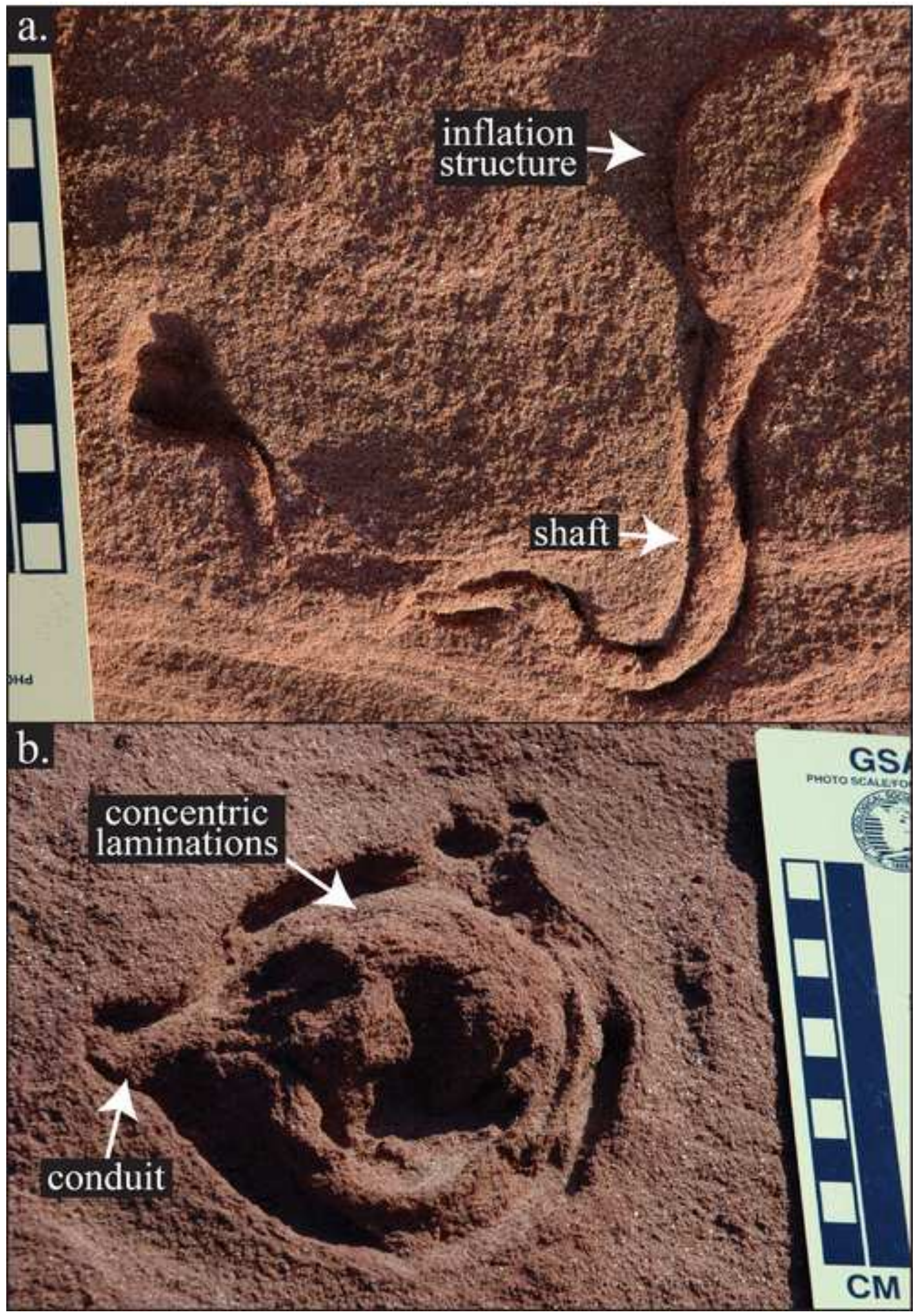




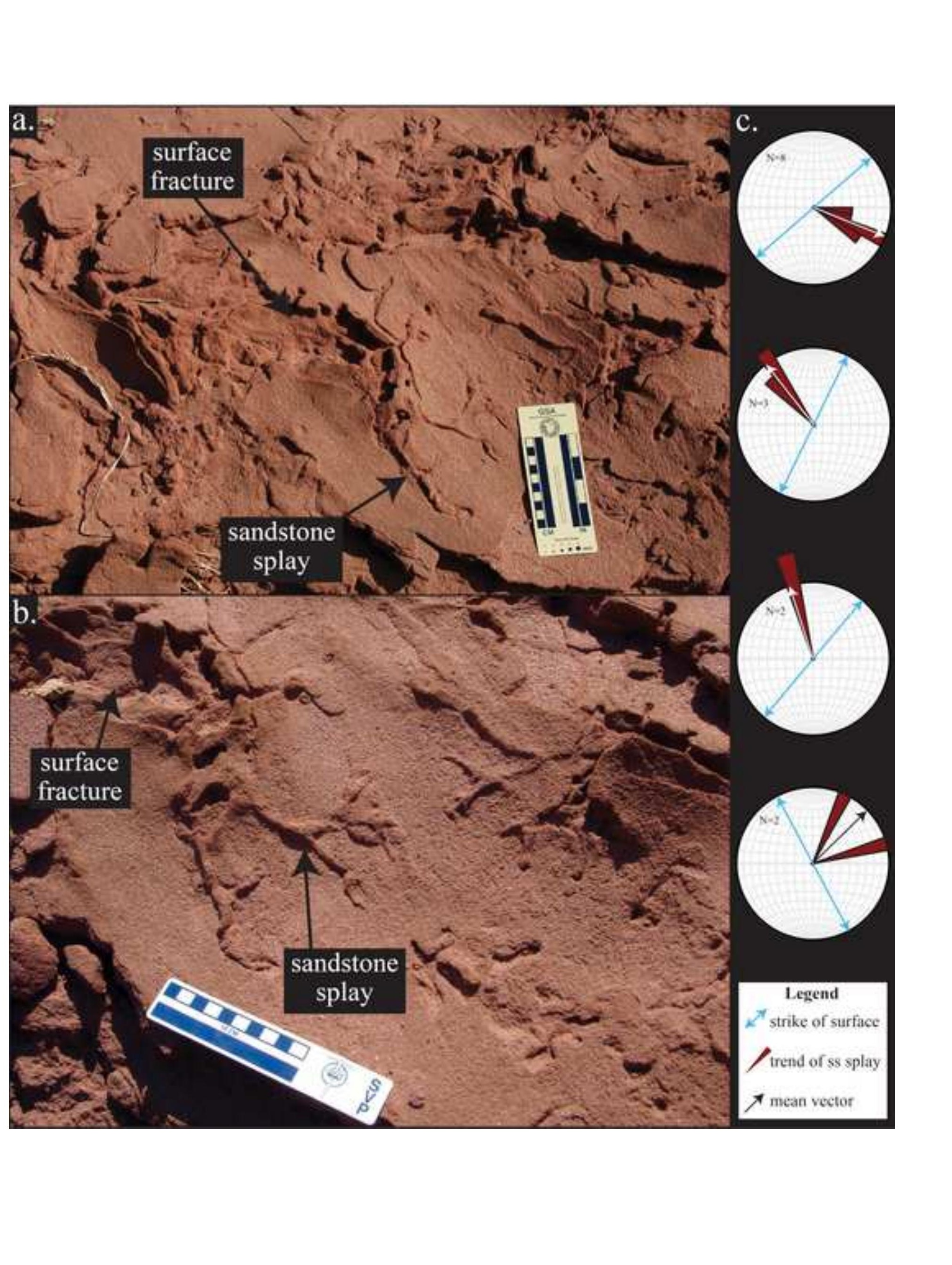

\section{.}
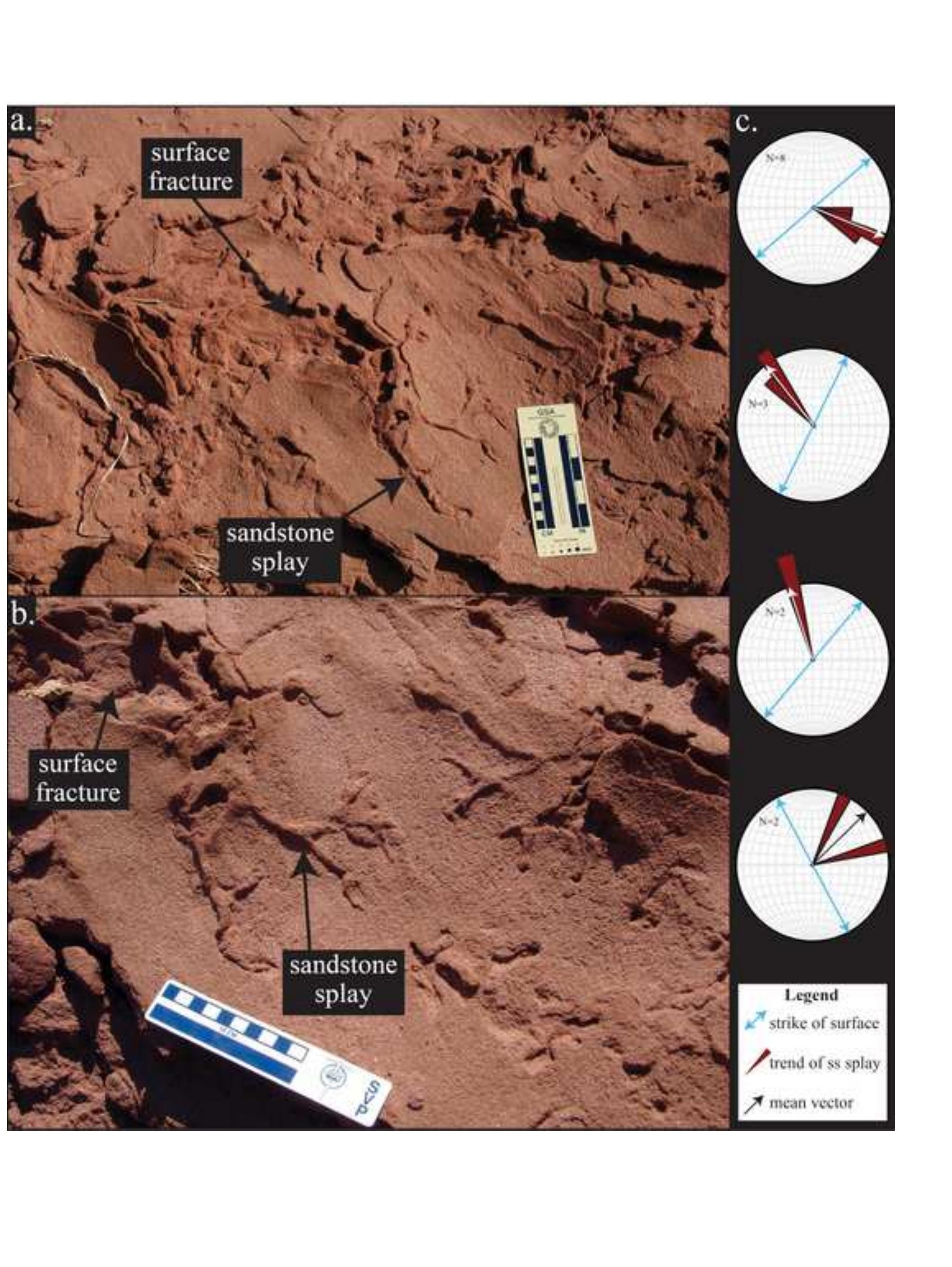


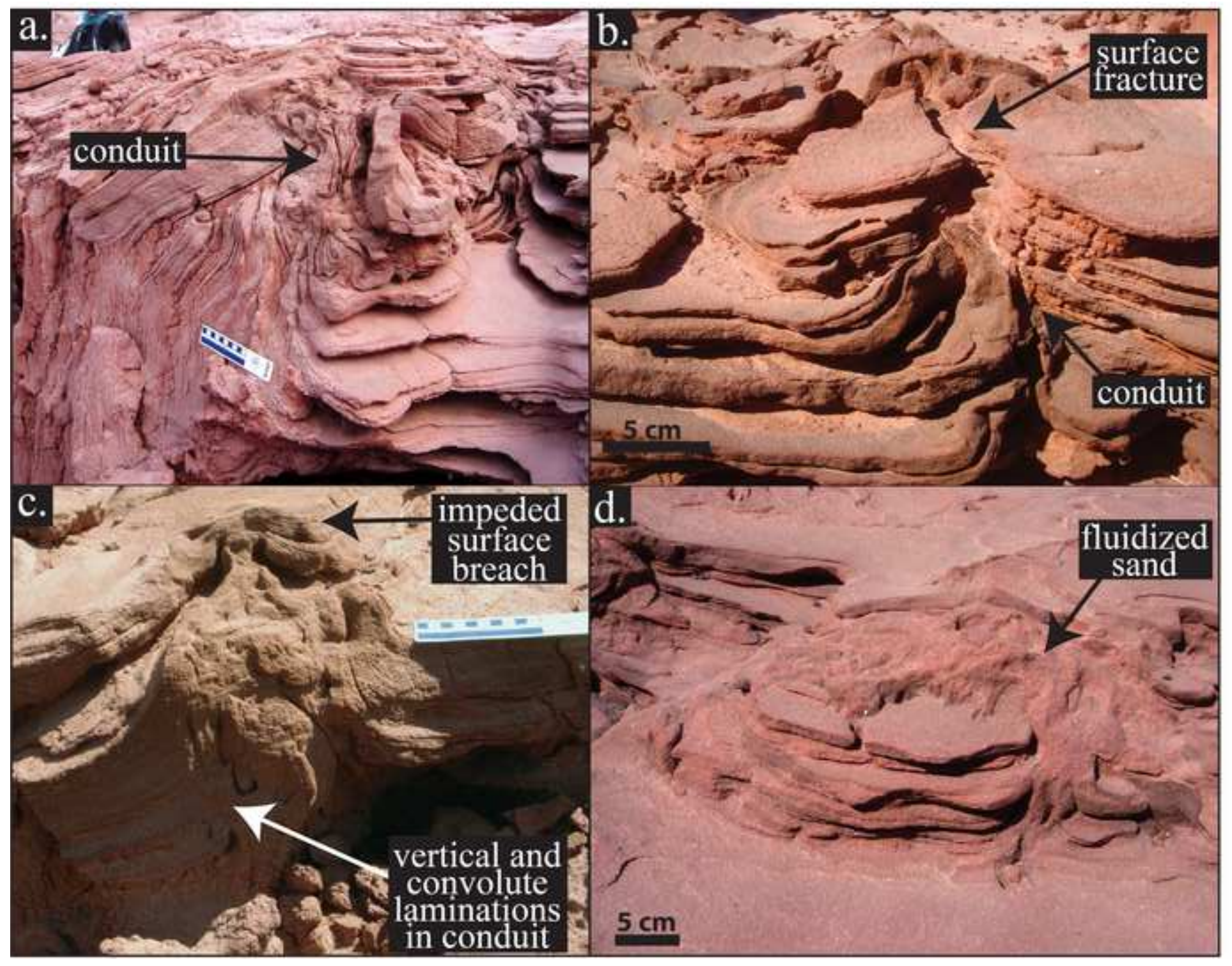




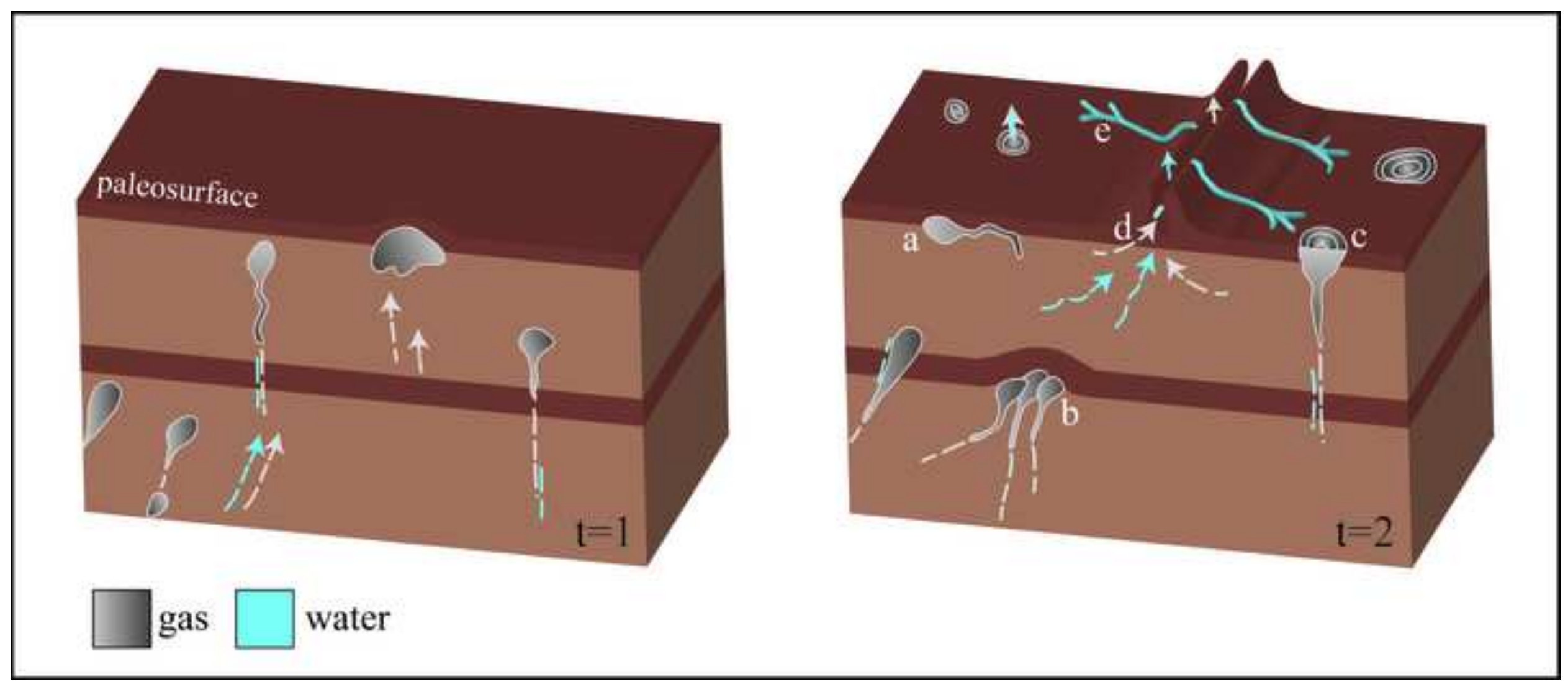

paleosurface

gas water 
Soft-sediment deformation structures generated via gas-escape
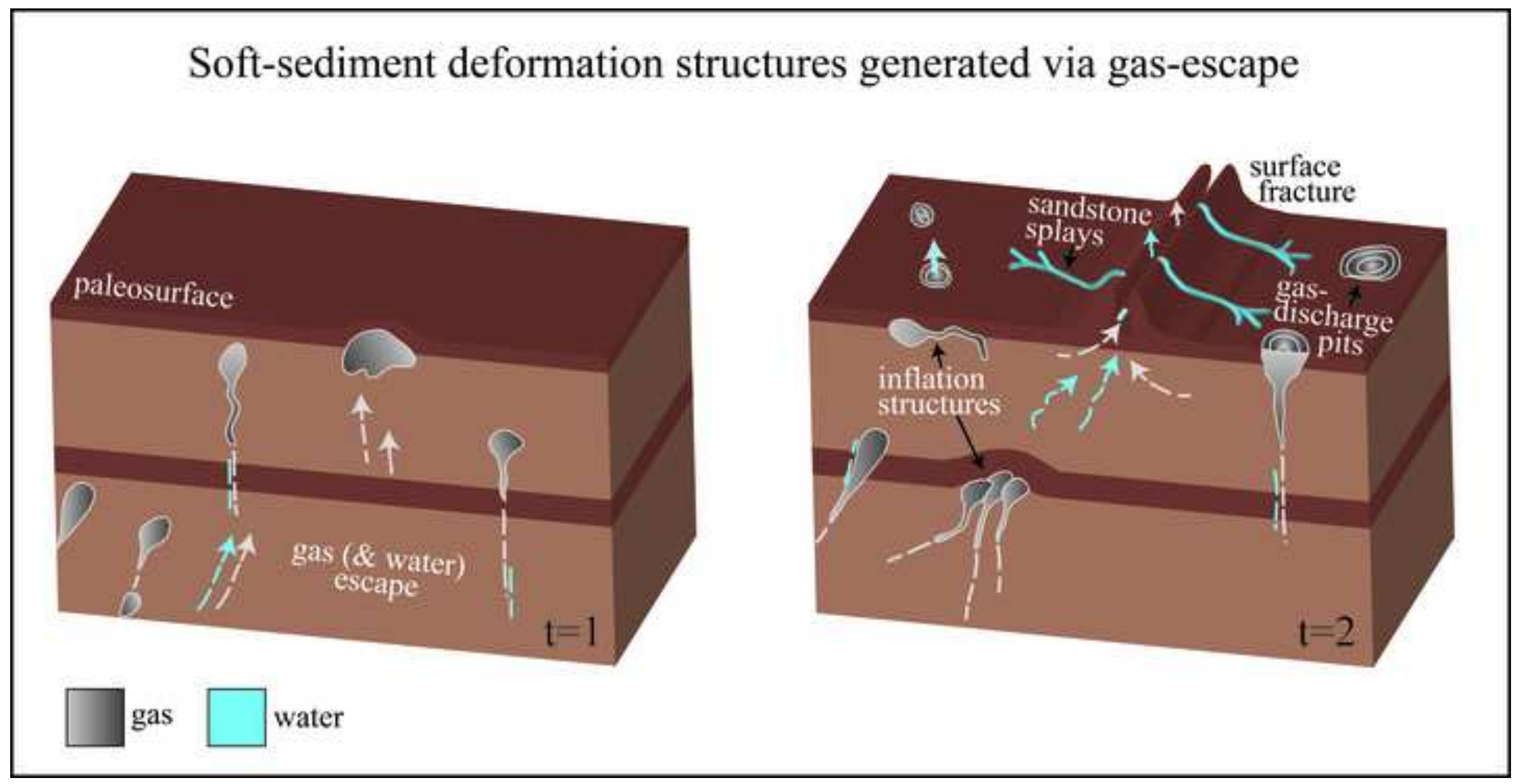